\title{
ÁNGEL SAAVEDRA, DUQUE DE RIVAS, EN LAS REVISTAS LITERARIAS ESPAÑOLAS
}

\author{
Antonio Arroyo Almaraz \\ AARROYOA@CCINF.UCM.ES \\ Universidad Complutense de Madrid
}

\begin{abstract}
Resumen
El presente trabajo muestra una panorámica de la presencia de Ángel Saavedra, duque de Rivas, en los periódicos y revistas de la época, destacando sus aportaciones: poemas publicados y no artículos del propio escritor. También recogemos las contribuciones críticas sobre Rivas realizadas por otros escritores: E. Ochoa, G. A. Bécquer...
\end{abstract}

Palabras clave: poesía, romanticismo, revistas literarias

\begin{abstract}
The present work shows an overview of the presence of Ángel Saavedra, duque de Rivas, in the newspapers and magazines of this period, emphasizing his contributions: published poems and not articles from the own writer. Also we gather the critical contributions on Rivas realized by other writers: E. Ochoa, G. A. Bécquer...
\end{abstract}

Key words: poetry, romanticism, literary magazines

Desde que G. Boussagol publicara en 1926 Ángel de Saavedra, duc de Rivas. Sa vie, son oeuvre poétique donde se abordó, posiblemente por primera vez, la recíproca influencia entre el escritor y la prensa de la época ${ }^{1}$, apenas se ha

1. Para esta cuestión remitimos al trabajo citado. He aquí un claro ejemplo señalado por Boussagol sobre cómo influyó la prensa en la obra de Rivas: «Nuestro poeta, lector de las revistas de su época, debió reparar en la sección de "Bella literatura" de El Panorama del 15 de agosto de 1839, pp. 101-105, con el título "La bala de oro", una fantasía novelesca en prosa sobre un episodio de la Batalla de Pavía. Poco después, la misma revista (pp.

Anales, 25, 2013, pp. 69-88 
vuelto a tratar esta vinculación. Los estudios de conjunto más recientes —ver bibliografía - abarcaron múltiples facetas de la obra del escritor, incluida la pictórica, pero escasamente dicha relación que fue también significativa como veremos. Tampoco la han recogido las ediciones y antologías de su obra literaria, por consiguiente, quedaba al descubierto la necesidad de profundizar en la labor iniciada por el hispanista francés.

$\mathrm{Su}$ estudio no fue completo; es cierto que no dispuso de los medios que hoy tenemos al alcance para investigar de forma más cómoda y exhaustiva la prensa del siglo XIX, por esa razón uno de los objetivos que nos proponemos es intentar completar sus referencias, para ello hemos elaborado un cuadro, como anexo a este artículo, donde aparece en letra redonda las citadas por Boussagol y en cursiva otras que hemos encontrado y centrarnos, por otro lado, en las aportaciones que pudo hacer Ángel Saavedra, desde su obra y su presencia en las revistas, en la modulación de los principios estéticos del Romanticismo así como en la configuración de los géneros literarios románticos, en el período de 1835-1868, pese a que nuestro cuadro amplíe las entradas hasta finales del siglo XIX para dar una visión más amplia sobre su proyección hacia el siglo Xx. Abordaremos dicha relación por géneros: teatro, poesía y narrativa, unido ello a otros elementos como la presencia pública de Rivas a

233-235) publicaba un resumen histórico de la cautividad de Francisco I: "Francisco I, Rey de Francia, preso en Madrid". Al final, en la p. 279 de la misma revista, figuraba el romance "Ambas á dos", del marqués de Molins, que muestra al rey de Francia prisionero desembarcando en Valencia y asistiendo a una velada "sarao" en casa del Comendador de Cúllar. Es difícil admitir que la Batalla de Pavía, suponiendo que concluyó el 20 de julio, haya determinado la publicación en El Panorama de tres fragmentos en los que Francisco I es el héroe y en el que la primera aparición sería impresa antes del 20 de agosto; pero si establecemos a Una Noche de Madrid en 1578 la fecha de 1839, podemos admitir que la idea de La Victoria de Pavía fue sugerida por los fragmentos anteriormente citados de El Panorama (...) Extraña coincidencia: La Mariposa publica en la p. 84 del t. I (20 de julio de 1839) una biografía de Bayard, El Panorama, de 1840, p. 58, publica un grabado representando el castillo de Bayard, y en la p. 84 (n. ${ }^{\circ}$ del 6 de febrero de 1840) "El Caballero Bayard, una biografía". Como antes de estas fechas Rivas no había publicado, que yo sepa, ningún romance sobre Bayard o Francisco I, hay que admitir que estas diversas publicaciones de las revistas de la época determinaron en él la creación de las obras dedicadas a este ciclo de las guerras de Italia. Otro detalle inquietante: La Mariposa del jueves, 14 de mayo de 1840, dice que se presentó en el Liceo el día 7 El Pastelero de Madrigal, en el que figura el seudo rey, Sebastián.

Estas coincidencias me conducen a edificar la hipótesis de que estas publicaciones de la época llevaron a Rivas a escribir: $1^{\circ}$, hacia finales de 1839 o a comienzos de 1840 , los tres romances, La Batalla (Victoria) de Pavía; La muerte de un caballero; Amor, honor $y$ valor; $2^{\circ}$, entre el 28 de septiembre y el 28 de octubre de 1840 , la comedia Solaces de un prisionero ó tres noches en Madrid; $3^{\circ}$, la comedia El Crisol de la Lealtad». [Capítulo X: «Las fuentes escritas: Romances Históricos». La traducción es nuestra]. 
través de la difusión de su imagen — grabado— o la novedad de las biografías en las revistas.

Las principales publicaciones a las que estuvo vinculado Rivas, bien por sus colaboraciones o por su inclusión en la crítica literaria romántica, fueron: la Revista Española (1834-1836²), El Artista (1835, 1836 y 1847), el Semanario Pintoresco Español (1841-1849) y el Museo de las familias (1853-1867); sin olvidar otras que podemos encontrar en el anexo donde aparece con menos frecuencia o significación. Fuera de la etapa romántica tuvo mayor presencia en La Ilustración Española y Americana (1875-1892), La Dinastía (18911896), La Lectura (1903-1914) y en Nuevo Mundo (1917-1933). De todas las revistas mencionadas fue El Artista la que más espacios y atención destinaron al escritor, uno de los principales representantes del cambio del clasicismo ilustrado al Romanticismo y, por consiguiente, baluarte del nuevo movimiento. Le dedicaron un total de diez entradas. Posteriormente, en la nueva tentativa de recuperar el primitivo espíritu romántico con la edición de El Artista. Revista Enciclopédica (1847), publicaron en ella el poema de Saavedra «Al Sol Poniente», escrito en Nápoles en 1844.

\section{Teatro}

Década de los treinta: El Artista

Como se ha dicho en varias ocasiones -Alonso Seoane, 2002; Ayala Aracil, 2002, entre otros-, fue esta revista la que defendió el presente romántico consolidándolo frente al clasicismo, y representó el punto de partida para una serie de revistas románticas a través de las cuales podemos conocer la evolución que tuvo el movimiento. Fueron Eugenio Ochoa, Federico Madrazo, el conde de Campo Alange ${ }^{3}$ y Leopoldo A. Cueto quienes defendieron con más interés la presencia y el valor que simbolizaba Ángel Saavedra, y dentro de su obra, sobre todo, Don Álvaro o la fuerza del sino, drama teatral del que apareció información sobre su puesta en escena en distintos montajes, tanto en Madrid como en Barcelona.

En el tomo I, dentro de las secciones Variedades y Crónica de Teatros, se dio en tres ocasiones noticias sobre el futuro estreno que se estaba preparando del Don Álvaro, de cómo iba de avanzada la escenografía que llevaba a cabo Blanchard, aprovechando siempre para apuntalar la defensa de la nueva

2. Con estas fechas señalamos el período en el que aparecen publicaciones de, o sobre, Ángel Saavedra. En un trabajo como este se hace difícil separar estos aspectos porque van unidos en muchos momentos.

3. Nos referiremos a él como Campo Alange que fue la firma que utilizó en la revista.

Anales, 25, 2013, pp. 69-88 
doctrina: «este drama está compuesto en el sentido de las modernas doctrinas literarias» $(\mathrm{I}, 72)$. Una vez estrenada la obra, Campo Alange escribió una extensa crítica de cuatro páginas donde destacaba la obra de Rivas como modelo de la nueva escuela, sintetizadora de dos valores fundamentales: «novedad de su contextura y de las libertades mas contrarias á muchas reglas» (I; 153); por tanto, dos elementos como sabemos acordes al ideario romántico: la originalidad y la libertad frente a la preceptiva ilustrada recogida por algunos tratadistas de poética como Santos Díaz González, Pedro de Estala o Agustín García de Arrieta, entre otros y, por consiguiente, según el modelo aristotélico defendido por Boileau, Luzán..., o presente en escritores como V. Alfieri (1749-1803). Así lo destacó Campo Alange (I;155): «Ya que nadie se atreve á juzgar las obras de la moderna escuela con los preceptos de Aristóteles».

También defendió la obra de los ataques que había recibido — polémicas con el Eco del Comercio, marzo de 1835; El Correo de las Damas, 21 de marzo y 7 de abril de 1835; Revista Española y Abeja...—. y con ello hizo una defensa de los cambios que representaba $(\mathrm{I} ; 155)$ :

Se dice que un defecto de D. Alvaro, inherente al desprecio de las unidades de lugar y de acción, es la forzosa repetición de exposiciones, y hasta cierto punto nos parece innegable este defecto; pero en nuestro concepto es de poquísima importancia, si se atiende á las ventajas que esta libertad proporciona.

No solo el rechazo a las unidades de lugar y acción, sino también la de tiempo, como más adelante veremos que señalaba Leopoldo $\mathrm{A}$. Cueto ${ }^{4}$, en un estudio que hace más pormenorizado a raíz de la reposición del drama (III; 110): «se deduce la necesidad de romper los grillos de la unidad de tiempo». Por tanto, rechazo de las unidades clásicas de espacio, tiempo y acción para lograr la libertad de creación e imaginación, como nos vuelve a recordar (III, 111):

Creemos que no toca al romanticismo ni mandar las unidades ni su indispensable infracción: esto fuera establecer principios dotrinales [sic] y estos principios son prisiones de la imaginación. El romanticismo es el libre alvedrío [sic] de los literatos: establecer reglas es vulnerarlo.

La defensa de la imaginación y la fantasía como parte de la naturaleza humana, como condición necesaria de cambio, la planteó Cueto en los siguientes términos (III, 108): «No somos de los exaltados, nosotros menos exaltados aunque profesamos el espíritu de esta escuela como el camino mas franco para que campée libre la imaginación». Un poco más adelante vuelve a decir (III,

4. En el tomo III, a raíz de la reposición de Don Álvaro o la fuerza del sino, fechada el 15 de mayo de 1835, el cuñado de Rivas, Leopoldo Augusto Cueto, le dedicó a la obra un extenso estudio de siete páginas que se publicó en el número 10 de 1836. 
111): «Dejemos pues á los ingenios entregarse á su propia inspiración, demos paso libre al vuelo de su fantasía». Otro rasgo significativo en la configuración genérica del Romanticismo fue la mezcla de los géneros, lo trágico y lo cómico, del lenguaje culto y el vulgar... (III, 111): «la mezcla de las situaciones trágicas con las vulgares, de las reflexiones filosóficas con las frases bajas de la plebe son copias fieles de la naturaleza».

No obstante, en esta defensa del ideario romántico llama la atención la pervivencia del carácter didáctico. La justificación del papel del dramaturgo todavía rezuma en estas fechas un sabor ilustrado, al igual que veremos en las críticas de M. José de Larra ${ }^{5}$ sobre el teatro y en particular de la comedia Tanto vales cuanto tienes de Ángel Saavedra. Campo Alange subraya esa finalidad didáctica y educativa (I; 156): «[el poeta] debe someterse á la voluntad del público, pero tiene la mision de instruirle y de dirijir sus gustos». Esta misma actitud se encuentra cuando aconseja suprimir algunos pasajes del Don Álvaro, que ya el autor había comenzado a realizar (I, 156): «le aconsejaríamos que hiciese desaparecer enteramente alguna escena: por ejemplo, la de los jugadores, que no es de muy buen efecto por la felonía de los oficiales».

E. Ochoa rechazó las primeras obras de Rivas -Doña Blanca de Castilla, Lanuza...- por considerarlas contrarias al nuevo teatro (I,177):

Dos obras dramáticas ha dado este poeta al teatro después de su vuelta á España: la comedia titulada Tanto vales cuanto tienes y el Don Alvaro ó la Fuerza del Sino. La primera, cuadro de costumbres, descolorido y frio como el género á que pertenece, composición mediana, digna de los primeros tiempos del autor; la segunda, tipo exacto del drama moderno, obra de estudio y de conciencia, llena de bellezas y de grandes defectos, sublime, trivial, religiosa, impía, terrible personificación del siglo XIX.

L. A. Cueto añadía, posteriormente, de la segunda obra (III, 107):

Los lances, aunque íntimamente conexos entre sí, no van naciendo sucesivamente de la conducta anterior de los personajes, como sucede en las comedias clásicas, sino del incontrastable poder del destino, de las inmutables

5. En La Revista Española del 6 de julio de 1834 apareció la crítica de Fígaro a la obra de Rivas. Como sabemos, Larra se esforzaba por educar al público de los teatros desde estas columnas de opinión. Obra tachada de nada original y sin interés: «Para los que creen que en el siglo XIX todo está dicho en literatura, no le quedaba otra corona que alcanzar al Sr. Saavedra». Posteriormente, sobre el estreno de Don Álvaro..., Larra se quedó en silencio y no escribió nada posiblemente porque lo que le preocupaba era ese afán de copiar y de asimilar los estereotipos románticos que venían de fuera, sobre todo de Francia, en lugar de haber profundizado en la liberación de los cánones que diera como resultado una literatura más propia, nuestra. Y por eso, posiblemente, celebró con una calurosa acogida la aparición de El Trovador (El Español, 4 de marzo de 1836). 
leyes de la suerte, de la fuerza del sino (...) en el D. Alvaro nadie puede inferir de las escenas antecedentes la progresión del argumento.

El carácter innovador de la moderna escuela vinculada a los jóvenes escritores y el final del clasicismo, por ende relacionado con la generación de los mayores, quedaba patente en estas otras palabras del crítico (III, 108): «La naciente Europa se ha declarado partidaria del bando libertador del yugo clásico, y la juventud española ha corrido á participar de la gloria de sus banderas». Cueto defendió la necesidad de un nuevo movimiento literario, el Romanticismo, que diera cabida a los nuevos dramas (III, 107):

Cualquiera que haya leido el Don Alvaro, conocerá que su argumento es la reunion de los sucesos mas interesantes de la vida de un desgraciado. De esta manera de formarlo, unido á la imaginación fogosa y productiva del poeta, ha resultado que rebosa de incidentes que si bien eminentemente dramáticos y magistralmente presentados, necesitan en nuestro sentir, para desenvolverse completamente, limites menos estrechos que los de un simple drama.

Sin embargo, no quedaba ajena la presencia del costumbrismo, como vemos en las siguientes palabras (III, 111): «El manejo de los modismos de la lengua, conocidos en toda su extensión y aplicados con admirable propiedad á los personages de las clases ínfimas que describe, el vivo colorido de estos retratos, y hasta la disposición local de estas escenas lo elevan al primer rango de los pintores de la baja sociedad».

\section{Otras revistas}

Nada nuevo aportaba el artículo de Antonio A. Galiano, publicado en la Revista Española de 1835, salvo apoyar una obra y a un amigo al que se siente unido ya que fue testigo directo de la composición del Don Álvaro, sin entrar ahora en los discutidos orígenes del texto aún no resueltos. Hace una defensa del drama romántico — 12 de abril—: «en cuanto al género del drama me confieso acalorado, tenazmente empeñado en introducirle en nuestra tierra porque le considero buen género y hasta nacional para que no le falte requisito de recomendación». Por otro lado, trata de contrarrestar, como habían hecho Ochoa y Campo Alange, los ataques recibidos; para ello se centra en la defensa de la libertad y la mezcla de géneros y lenguajes, como consecuencia de esa libertad:

Se ataca el romanticismo, ó la regla de ausencia de reglas que así se llama (...), hay en su composición escenas bajas en que se habla mala prosa (...). Las hay porque juzgó el autor que el teatro debe ser una copia de la vida humana, en que lo alto y lo bajo, lo sublime y lo grosero, lo burlesco y lo triste, se tocan y cruzan entre sí á cada paso. 


\section{Década de los cuarenta}

Aparece una nueva crítica que refuerza las ideas planteadas anteriormente por Ochoa, Campo Alange, Cueto y Alcalá Galiano; ahora a través del Semanario Pintoresco Español y El Siglo Pintoresco. Mesonero Romanos en su «Rápida ojeada sobre la Historia del Teatro Español»-Semanario, 11 de febrero de 1842, pp. 397-400_, solo menciona Lanuza de la etapa de las tragedias neoclásicas de Rivas restándole valor literario — «tributos pagados á las circunstancias políticas de la nación»-y sitúa a Don Álvaro como el primer drama de la escuela romántica, cosa que como sabemos no era cierta aunque sí la más relevante, y apuntó que Solaces de un prisionero, obra de 1840, se aparta de un Romanticismo estereotipado ya en aquellos momentos:

el drama aparece querer aproximarse á la comedia antigua, apartándose de la exageración y los horrores de la escuela romántica; y á esta nueva senda le han seguido todos los autores ya citados, y otros que de nuevo han aparecido. El Señor Saavedra, hoy Duque de Rivas, presentó hace pocos años su drama Solaces de un prisionero...

Igual valoración encontramos con otra obra de Rivas, El crisol de la lealtad de 1842, de la que extraemos la siguiente apreciación encontrada en la sección «Revista de Teatros» del Semanario —9 de julio de 1843, p. 222-:

El Crisol de la lealtad, es una feliz escepción del hecho general que asentamos al principio, es á nuestros ojos un paso de progreso, y no dudamos preferirla á la Morisca de Alajuar, y hasta á los Solaces de un prisionero; hay en ella mas interés, mas novedad, menos monotonía de duelos, citas y tapadas, menos afectación de imitar la escuela de Calderon, escollo principal de las obras dramáticas del Duque de Rivas.

Gavino Tejado en su extenso artículo dedicado a Rivas en El Siglo Pintoresco -1 noviembre de 1845, pp. 220-226- se limitó a hacer una exaltación del escritor carente de toda visión crítica.

Finalmente, La Ilustración Española y Americana -15 de diciembre de 1875-, publicó un estudio de Leopoldo Augusto Cueto dedicado al drama fantástico El desengaño en un sueño, obra de 1842, que tildó de leyenda fantástica. Reconoció en él que el transcurso de cerca de cuarenta años, desde que se estrenara Don Álvaro hasta esos momentos, había conseguido desnaturalizar el discurso de lo fantástico, por lo que resultaba una lectura de la obra difícil de encajar: «El transcurso de más de treinta años ha modificado grandemente el espíritu de las gentes. Nadie se aviene ahora fácilmente a creer en lo imposible». Planteó también la dificultad de la representación de la obra, aunque había sido puesta en escena anteriormente por Antonio Vico. Realizó un análisis de sus fuentes, principalmente la presencia de Calderón, pese a que el 
desarrollo del drama parte de un texto encontrado que originó el interés y el argumento para esta otra de Rivas: Sueños hay que lecciones son, ó efectos del desengaño, drama alegórico en cinco actos de 1817, refundida por D. M. A. No obstante, nos encontramos ante un drama renovado.

Tras la muerte de Rivas se hace una estimación del conjunto de su obra y de su papel como dramaturgo donde se refuerzan las ideas apuntadas. Las necrologías ${ }^{6}$ no aportaron nada nuevo, como por otro lado era de esperar. La más completa en cuanto a datos biográficos fue la de José Muñoz Gaviria (Museo de las Familias, 1 de julio de 1865), quien le reconoce como poeta romántico significativo. Otra fue la de G. A. Bécquer (El Museo Universal, 2 de julio de 1865), quien subrayó su condición, por encima de todo, de poeta.

\section{Poesía}

\section{Romances históricos}

En la poesía el protagonismo fue para los Romances Históricos (1841): poesía narrativa de asunto histórico en la que descansaba en buena medida el espíritu de la nación, su naturaleza humana y social. La forma popular del romance y la recuperación del verso de arte menor representaban la verdadera poesía de tradición nacional; así lo reflejó Rivas en el prólogo a los Romances, y también lo destacó Ochoa —El Artista, t. I, p. 177-: «Entre las poesías sueltas del Sr. Saavedra merecen particular mencion los Romances históricos (...) en que se hallan espresados en dulces versos los mas sagrados afectos de la naturaleza. Estos son los verdaderos manantiales de la inspiración, la fuente Castalia de los poetas modernos». Dos romances aparecieron completos en la Revista de Madrid en 1838, «La Buenaventura» y «Bailén». Fragmentos de ellos vieron la luz en distintos periódicos: El Corresponsal en 1841; del romance «Los recuerdos de un grande hombre» en el Semanario Pintoresco Español de 1849; de "Una antigualla de Sevilla» en el Museo de las Familias en 1856; de «La victoria de Pavia» en el Museo de las Familias de 1861. La edición de

6. Museo de las Familias, 1 de julio de 1865, Jose Muñoz y Gaviria: «Estudios Biográficos. Don Angel Saavedra, Duque de Rivas»; Escenas Contemporáneas, 1 de julio de 1865, pp. 238-239, Leopoldo A. de Cueto: «Discurso Necrológico y Literario». En la misma revista y fecha, pp. 305-307, «Discurso del Escelentísimo señor Duque de Rivas», por José Amador de los Ríos. Anteriormente, p. 189, en «Necrología» Félix Janer, menciona a Rivas junto a los también fallecidos Alcalá Galiano, Pidal y Ventura de la Vega. El Museo Universal, 2 de julio de 1865, pp. 210-212, «El duque de Rivas» por Gustavo Adolfo Bécquer; incluye el dibujo de una medalla acuñada en París con la efigie de Rivas. El Angel del Hogar, 30 de junio de 1865, pp. 190-192, sección «Revista de la Semana», por Eusebio Blasco. Fue recordado en periódicos posteriores como en El Tajo, del 16 de junio de 1867. 
los Romances Históricos se reseñó en el citado El Corresponsal de 1841. Artículo firmado por Diego Coello que apareció en la sección Folletín: «Crítica Literaria. Romances Históricos del Sr. D. Angel Saavedra, Duque de Rivas», donde destacó la vinculación de los Romances al Romanticismo, así como la concepción del romance como base de la poesía dramática o el papel de la historia medieval en la configuración de la idea de la nación. Y en El Pensamiento de ese mismo año, que incluyó también un artículo extenso de Enrique Gil titulado «Literatura Contemporánea. Romances Históricos por Don Angel Saavedra, Duque de Rivas» donde valoró a Rivas como uno de los principales poetas románticos; el texto va acompañado de un estudio pormenorizado de los romances, con fragmentos de ellos. Diez años después, en 1851, La España publicó diferentes partes de la leyenda «La azucena milagrosa» en un estudio de Eugenio Ochoa sobre la obra de Rivas, de la que destacó elementos como la imaginación y la fantasía esenciales en su composición, que la definían como netamente romántica.

\section{Poesía lírica}

Hay que destacar la publicación de «El Faro de Malta» [1828] (El Artista, 1835), donde se aprecia un lenguaje romántico que exalta lo irracional y el papel de la naturaleza como aliada del espíritu humano: «terrible noche, ronco huracán, borrascosas nubes, tinieblas impalpables...»; en medio de todo ello, el faro como «luz de paz y vida», «Les adviertes su engaño./ Asi de la razon arde la antorcha,/ En medio del furor de las pasiones, / O de aleves halagos de Fortuna,/ A los ojos del alma [...] Me traen nuevas amargas, y renglones/ con lágrimas escritos», por lo que Ochoa afirmó: «El romanticismo es hijo de las lágrimas» (I, 177). Este poema sintetiza algunos de los principios estéticos del movimiento, y Malta representó para Rivas la entrada de lleno en la literatura romántica a través de su amistad con Frere y otros amigos ingleses.

También publicó el poema «A un arroyo. Meditación», diez décimas con una clara presencia calderoniana que aparecieron en la Revista de España y del Estranjero, tomo VI, 1843. Un soneto dedicado a la Reina en El Cisne, 1838. «Al sol poniente», poema fechado en Nápoles el 30 de junio de 1844 -El Artista, 1847, ya citado- - «En el álbum de un napolitano» $\mathrm{y}$ «Versos escritos en un álbum»-Escenas Contemporáneas, 1882-y «Cristobal Colón» composición escrita en Londres en 1824 — La Ilustración Española y Americana, 12 de octubre de 1892, aniversario del Descubrimiento-. Algunos de estos poemas se divulgaron por primera vez en prensa, como así se deduce al leer en la revista, en el caso de «Al sol poniente»: «Esta es una de las bellas composiciones que el poeta ha escrito durante su permanencia en Italia, y que piensa 
publicar con otras que formarán un grueso tomo»; o sobre las redondillas publicadas en Escenas Contemporáneas: «El director de esta REVISTA conserva el manuscrito de estos versos que le dió su esclarecido amigo el eminente poeta Sr. D. Angel de Saavedra, Duque de Rivas».

\section{Rivas en las creaciones poéticas de otros autores}

Como poeta y dramaturgo apareció en algunos poemas de otros poetas que se publicaron en prensa, como en El Heraldo del 31 de julio de 1841 que incluyó uno de Zorrilla ${ }^{7}$ donde recuerda su estancia en Sevilla, en la casa del Duque de Rivas. O en el Museo de las familias, del 1 de enero de 1865, donde José Muñoz Gaviria, en la citada necrológica sobre Rivas, incluyó el soneto que Juan Nicasio Gallego había dedicado a Ángel Saavedra al publicar su primer tomo de poesías —Cartuja de Jerez, 1819-:

Tú á quien afable concedió el destino digna ofrenda á tu ingenio soberano manejar del Aminta castellano la dulce lira y el pincel divino. Vibrando el plectro, y animando el lino logras, Saavedra, con dichosa mano, vencer las glorias del cantor troyano, robar las gracias del pintor de Urbino. Lógralo, logra ya, si mas clemente se muestra acaso la áspera fortuna que hoy no me deje en blanco con loarte tejer nuevas coronas á tu frente ya esclarecida por tu ilustre cuna, ya decorada del laurel de Marte.

7. «Nunca olvidaré las noches/ que en la encantada Sevilla/ en grata amistad sencilla/ franca sociedad goce,/ en un jardín que entoldaban/ mil fragantes limoneros/ y en cuyos frescos senderos/ sobre flores iba a pie.// Siempre, ;oh Angel!/ la memoria/ de aquellos serenos días/ embellecerá las mías/ recordando tu jardín/ mas bello con el silencio/ de su soledad tranquila/ que el gran salón que vacila/ con el rumor del festín// Siempre que miro la luna/ brillar en el firmamento/ recuerdo tu apartamiento/ tu familia y tu amistad/ y à las leves auras ruego/ que te lleven, Angel mío, un suspiro que te envío/ en fé de fraternidad// Cuando en el golfo azulado/ que en estas playas ondea/ la lámpara que platea/ la noche, veas brillar,/ piensa, ¡oh Angel! que hay un hombre/ que su esplendor contemplando/ está en Nápoles pensando/ para volverte à abrazar///». Según las palabras de Eugenio Ochoa, deducimos que a este poema contestó Rivas dedicando a Zorrilla su leyenda en verso «La azucena milagrosa»: «Precédele una introducción dirijida al excelente poema de don José Zorrilla, a quien el autor dedica su obra, en correspondencia de otra que el primero le dedicó a él» —La España, 10 de julio de 1851—. 
El 22 de junio de 1875, La Ilustración Española y Americana incluyó un poema de Patricio de la Escosura titulado «Epístola, al Excmo Sr. D. Juan Nicasio Gallego» donde cita a numerosos escritores, entre ellos a Rivas: «Poeta de DON ALVARO y MUDARRA,/ Pintor también, y prócer, y soldado (30),/ Como en los aires la nervuda garra/ El águila caudal tiende, y la presa/ Que apenas vió asegura y la desgarra,/ Acude ardiente á la sublime empresa,/ Su vuelo alzando hasta el celeste emporio,/ Quien poeta y no más vivir profesa./ ¡Salve, cantor de Sanchos y de Tenorios!/ ¡Salve, de luz estrella rutilante.//». [(30) D. Angel Saavedra, Duque de Rivas].

\section{Narrativa}

En el plano de la prosa de viajes se encuentran el «Viaje a las ruinas de Pesto» y el «Viaje al Vesubio», fechadas en Nápoles, mayo de 1844 que aparecieron ese mismo año en la Revista de España y del Estranjero. Anteriormente se habían publicado "Los Hércules» ${ }^{8}$ en La lira andaluza de 1838 (ver nota 12) y «El hospedador de provincias» —entrega 44 del tomo I-y posteriormente «El ventero» - entrega 17 del tomo II- en la colección colectiva costumbrista Los españoles pintados por sí mismos (1843-1844), sucesión coleccionable de artículos que salían en fascículos de uno solo acompañado en ocasiones de láminas tiradas aparte así como grabados y adornos; cada tomo se encuadernaba.

El «Viaje a las ruinas de Pesto» y el «Viaje al Vesubio» los escribió Rivas al poco tiempo de ser nombrado Embajador de España en el Reino de las Dos Sicilias, tras su llegada a Nápoles a comienzos de marzo donde presentó sus credenciales ante Fernando II. Fue embajador hasta el 10 de julio de 1850. En estas narraciones Rivas se sale del modelo romántico a favor de una mirada más objetiva de la realidad carente de toda proyección emocional; una mirada que se desdobla entre el relato de lo que ve y el relato de lo que sabe sobre el pasado y los restos arquitectónicos; huellas que el arte había dejado a lo largo de su historia. El primer viaje es una excursión de cuatro días para visitar Pesto — tres jornadas de ida recorriendo Pompeya, Pagani, Amalfi..., y una jornada de vuelta recorriendo Vietri, La Cava, Nocera y de nuevo Nápoles; en total cerca de $140 \mathrm{~km}$.- que comenzó en el mes de mayo, dos meses después de su llegada a Nápoles, y firma el texto el día 30. Apenas aparece el nombre de los personajes que le acompañan salvo el duque de Montebello, embajador en Francia. Poco después inició el segundo viaje, una ascensión al Vesubio,

8. Ver la edición contemporánea de «Los Hércules» en El artículo literario y la narrativa breve del romanticismo español, pp. 407-422. 
la noche del 31 de julio. Aquí aparecen los personajes con más precisión: la joven condesa española Escláfani y su esposo, el príncipe Schwarzenberg y el señor Yrizar, magistrado de Filipinas.

Imbuido por la historia de Nápoles y los acontecimientos políticos que le tocó vivir, escribió el libro Sublevación de Nápoles capitaneada por Masaniello, con sus antecedentes y consecuencias, hasta el restablecimiento del gobierno español (1847); obra encargada por la Academia de la Historia de Nápoles, que publicó posteriormente en el Museo de las Familias con el título «Ocho días de reinado o la verdadera historia de Masaniello». Aparecía con ilustraciones el 25 de junio de 1853 y los sucesivos días 25 de cada mes hasta completar las cinco entregas que abarcó, desde junio hasta octubre. Tuvo un carácter didáctico, es decir, Masaniello como modelo que había que reconocer (junio, p. 121):

nuestros contemporáneos encontrarán peripecias muy dramáticas y lecciones provechosas (...) el mayor castigo que puede imponerse á los supuestos novadores que trastornan el mundo, es probarles que no inventan nada, y que no hacen mas que copiarse unos á otros, sin provecho alguno para nadie, ni aun para ellos mismos. Jamás se vió tan palpable esta moralidad como en la vida y muerte de Masaniello.

Años después publicó su Breve reseña de la Historia del Reino de las Dos Sicilias 一julio, 1855-.

\section{Rivas en los grabados y biografías}

Para terminar, nos queda mencionar otras dos presencias de Rivas en la prensa. En la revista ilustrada El Artista se incluyeron dos litografías dedicadas al escritor: una, fue un retrato realizado por Federico Madrazo y, la otra, el dibujo de Carlos Luis de Ribera de Rui-Velázquez, personaje del Moro Expósito. Como sabemos El Artista incorporó el grabado como material informativo, sobre soporte litográfico, integrando el discurso lingüístico y el trazado pictórico, sobre todo en las Galerías de Ochoa. La difusión divulgadora que realizaron a través, en este caso, del retrato fue significativa para dar a conocer también la imagen del poeta al que solo se le podía leer a través de sus escritos, de esta manera se incorporaba por primera vez la imagen de Ángel Saavedra. En muchos casos son imágenes que se adaptan a la iconografía y estética del Romanticismo, más concretamente la ilustración de tema histórico, como la del personaje Rui-Velázquez.

Eugenio Ochoa dedicó a Rivas la segunda «Galería de Injenios Contemporáneos» en El Artista —entrega XV—, la primera fue para Martínez de la Rosa. Las biografías de personajes contemporáneos fueron otra de las novedades que introdujo la revista. Es aquí donde Ochoa (I, 175) destacó, al trazar el 
perfil biográfico del escritor, su condición de paradigma de la nueva escuela y símbolo del abandono de los principios ilustrados: «Toda esta época de la vida literaria del Sr. Saavedra fue exclusivamente dedicada al culto del mas riguroso clasicismo, y así todas sus composiciones de entonces carecen del carácter verdaderamente español y original (...) [fue] El Desterrado; primero y feliz ensayo romántico de este ilustre poeta».

Son muchos los referentes citados que permiten concluir y apreciar el papel significativo que tuvo Ángel Saavedra, no del todo reconocido. Creemos que no hemos podido recoger todas sus contribuciones en la prensa, seguramente trabajos futuros podrán añadir más citas periodísticas, así como también las contribuciones y el reconocimiento que tuvo tanto en vida como después a través de las revistas literarias españolas, pero nos sentimos satisfechos por el hecho de aportar algo en lo que considerábamos un hueco no tratado por la crítica literaria que refuerza la visión del Duque de Rivas como escritor emblemático del Romanticismo español.

Anexo $^{9}$

1811 Periódico del Estado Mayor, publicado semestralmente durante todo el año: lo dirige Ángel Saavedra y contribuye a su redacción. De La Isla de León, 1810-12 (no localizado).

1813 El Conciso, 28 enero, Cádiz. Presencia de Ángel Saavedra. Cortes del día 26 de enero.

1813 El Conciso, 13 marzo, Cádiz. Ídem del día 11 de marzo.

1813 El Redactor General (de España) de Cádiz, 1 de noviembre. Según N. Pastor Díaz, Rivas escribió artículos y sátiras en verso, sin embargo ni Boussagol ni nosotros hemos encontrado nada al respecto $^{10}$.

9. Como ya hemos señalado, el texto que está en redonda pertenece a G. Boussagol, y el que está en cursiva, salvo la que corresponde a los títulos de obras, es nuestro y complementa sus aportaciones. Pese a que algunas citas del hispanista no las hemos encontrado las dejamos en el anexo como referentes.

10. Según Boussagol: «N. Pastor Diaz afirma (I, 38) que Rivas se impregnó en Cádiz de la «cólera política», y que escribió en El Redactor general artículos y sátiras en verso empapadas de espíritu liberal. Parece difícil admitir que la naturaleza tan impresionable de Rivas permaneciese insensible a los fermentos liberales que poblaban la atmósfera enrarecida de Cádiz; debemos creer a N. Pastor Díaz, que parece hablar por Rivas. Sin embargo, todo este pasaje (pp. 38 y 39) es de una cronología absurda, y destruye toda confianza que pudiéramos tener en la biografía; por otro lado, no he encontrado nada de Rivas en El Redactor general de España, cuyo primer número es del lunes 1 de noviembre de 1813, cuando Rivas deja Cádiz por Sevilla y se ocupaba de hacer imprimir 
1824 Ocios Españoles Emigrados ${ }^{11}$

1834 La Revista Española, 6 de julio de 1834. Crítica teatral realizada por M. José de Larra a la obra Tanto vales cuanto tienes, representada en el Teatro Príncipe.

1834 La Revista Española, tres artículos de A. Alcalá Galiano sobre el estreno y las nueve representaciones de Don Álvaro. 21 de marzo: informa del estreno de la obra; continúa el 12 de abril, y termina el 7 de mayo.

1835 Polémica sobre Don Álvaro: El Correo de las Damas, 21 de marzo y 7 de abril. También en el Eco del Comercio, marzo.

1835-1836 El Artista, Tomo I: p. 72, sección Variedades, se mencionan los ensayos para la puesta en escena de Don Álvaro..., y los decorados que está realizando Blanchard. P. 132, Variedades: se informa del próximo estreno de la obra. P. 144, Crónica de Teatros: se anuncia el estreno que se realizará ese mismo día. P. 153, reseña del estreno de Don Álvaro... en el Teatro Príncipe, realizada por Campo Alange. P. 174, retrato de Rivas en una lámina de Federico Madrazo. P. 175, 2. ${ }^{a}$ Galería de Ingenios Contemporáneos, de Eugenio Ochoa, dedicada a Rivas [incluye el poema «El Faro de Malta»]. P. 240, lámina del Moro Expósito. Tomo II: p. 39, se menciona el Don Álvaro en un artículo de Ochoa: «Publicaciones Recientes». P. 264, se le menciona como presidente del Ateneo Científico y Literario. Tomo III: pp. 106-108 y 110-114 «Examen del Don Álvaro o la fuerza del sino» de Leopoldo Augusto Cueto.

1836 Revista Española, 1 de enero: información sobre la intervención de Rivas en el Estamento de Próceres; 19 del mismo mes, se menciona que Malek-Adhel forma parte del Circo Olímpico.

$1838 \quad$ El Cisne, periódico de literatura y bellas artes ${ }^{12}: 21$ de julio, soneto de Rivas dedicado a la reina regente por su cumpleaños.

sus Poesías. Si fue liberal exaltado en 1812, se reconvirtió rápidamente en «fernandista». [Cap. II, apartado II. La traducción es nuestra].

11. Según Boussagol, Rivas: «Cuando llega a Londres, en mayo de 1824, se publica el número dos del periódico mensual, "Ocios españoles emigrados»; desde el mes de agosto (n. ${ }^{\circ}$ ), hace aparecer en él a su Desterrado, del cual se publica un fragmento de la traducción inglesa en el número 9, del mes de diciembre». [Cap. II, apartado III. La traducción es nuestra].

12. Según Boussagol: «Liceo artístico y literario; las sesiones se cuentan en El Cisne periódico de Literatura y bellas artes cuyo primer número es el 3 de junio de 1838. Esta publicación no basta para acabar con el stock de poesías románticas de los escritores de la región, y su producción llena todavía dos números de La lira andaluza. La presentación 
1838 La lira andaluza: «Los Hércules», 15 de junio.

1838 Revista de Madrid, 2. ${ }^{a}$ serie, tomo II, se publican los romances completos de Rivas: «La buenaventura» (13 de julio; pp. 210224) y «Bailén» (pp. 328-340).

1841 El Corresponsal, 10 de febrero: apartado Folletín, crítica literaria: «Romances históricos del Sr. D. Angel Saavedra, Duque de Rivas». Diego Coello; incluye fragmentos de algunos romances.

1841 El Pensamiento, tomo I, $3^{a}$ entrega, Enrique Gil y Carrasco publica un artículo sobre los Romances históricos.

1842 El Pasatiempo, 21 de septiembre. Se cita a Rivas como influencia en El Trovador ${ }^{13}$.

1842 Semanario Pintoresco Español, 11 de febrero: «Rápida ojeada sobre La Historia del Teatro Español/ Epoca Actual», de R. de Mesonero Romanos, incluye a Rivas en distintas etapas.

1843 El Genio de la libertad, 12 de octubre: informa de la representación en Palma de la obra Solaces de un prisionero o tres noches en Madrid.

de informes de las sesiones del Liceo testifica el rango preeminente que Rivas ocupa en este medio. El 15 de junio, lee «El castillo de Montiel», publicado en los Romances Históricos bajo el título de «El Fratricidio». El 21 de julio, el Liceo celebra el cumpleaños de la reina regente (...) y se presta especial atención a que se publica en «El Cisne», un soneto del Duque de Rivas a S. M. la augusta Reina Regente. Del mismo duque, El Cisne publica también «A un arroyo»; y en su crítica acerca de la segunda entrega de La Lira Andaluza, sólo hace una excepción a favor de la fantasía en prosa titulada «Los Hércules», firmada con una S. y que se encuentra en el tomo V (pp. 328-336) de la edición de 1854-1855 de las obras completas de Rivas». [Cap. II, apartado VI. La traducción es nuestra]. Esta información no la hemos podido contrastar.

13. «En El Pasatiempo del 21 de septiembre de 1842, un crítico, que firma R. escribe las siguientes líneas, en las que compara El Trovador con D. Álvaro...: Ayer tarde, dice, vimos El Trovador. Esta obra «es ya una tradición para nosotros... Un rastro de luz había brillado dos años antes, y servía ya de faro misterioso para guiar aunque por medio de principios, á los jóvenes talentos que vivían entre las nieblas de la literatura dramática, poco menos que eclipsada. Acaso la misma grandeza del pensamiento, altamente moral y filosófico, que presidió á la concepción del drama de don Ángel Saavedra, duque de Rivas, fué una razon para que 'La fuerza del sino' no produgese más prontos y fecundos resultados, para la era naciente del romanticismo. Su drama se iba á ver con fé y religiosidad como un misterio que no se concibe, pero cuya sublimidad se siente; así es que más bien inspira asombro que convicción; y el entendimiento se creía más en su deber admirándolo, que tratando de imitar un cuadro que ni aun alcanzaba á comprender sin extrañeza, El Trovador, fué la estrella de luz más clara y apacible que iluminando lo más fácil del ya trazado y escabroso camino, sirvió para hacernos ver que no era intransitable el enmarañado sendero» [Nota 536 en el apartado «Visión de Conjunto y Conclusiones». La traducción es nuestra].

Anales, 25, 2013, pp. 69-88 
1843 Semanario Pintoresco Español, 9 de julio: «Revista de Teatro/ Mes de junio»: Crisol de la lealtad, Teatro Príncipe.

1843 Revista de España y del Estranjero, tomo VI, incluye el poema «A un arroyo. Meditacion».

1844 Revista de España, 30 de mayo: «Viaje a las ruinas de Pesto», «Viaje al Vesubio», tomo IX pp. 145-167 y tomo VIII pp. 333-344 [realmente es: tomo IX, pp. 333-349].

1844 El Heraldo, 31 de julio, poema de Zorrilla donde recuerda su estancia en Sevilla, en la casa del Duque de Rivas.

1844 Revista de España, sección: Crítica Literaria, de Fermín Gonzalo Moron, «El Duque de Rivas, Considerado como poeta dramático». Tomo IX, pp. 42-52 y 117-128 (anuncia su continuación pero no la hemos encontrado). Incluye fragmentos muy amplios del Don Álvaro...

1845 El Siglo Pintoresco, t. I, pp. 220-226, 1 de noviembre, «Escritores contemporáneos. El Duque de Rivas», de Gavino Tejado, con ilustración de V. Castello.

1846 Semanario Pintoresco Español, 2 de agosto, sección Crónica: informa de la puesta en escena de Don Álvaro o la fuerza del sino, en el Teatro de la Cruz.

1847 El Artista, 14 de marzo: incluye el poema «Al sol poniente», fechado en Nápoles, 30 de junio de 1844.

1848 El genio de la libertad, 16 de julio: información en la sección Teatro de la representación de Solaces de un prisionero.

1849 Semanario Pintoresco Español, 19 de agosto, p. 259: «La Rábida» de Amador de los Ríos, incluye a Rivas: fragmento del romance «Los recuerdos de un grande hombre». 26 de agosto, p. 268: «Apuntes» de Cánovas, lo cita; menciona la Revue de deux monde donde se ocuparon de la obra de Rivas: "... Masaniello». 25 de noviembre, p. 370: «Los Infantes de Lara» de Luis M. ${ }^{a}$ Ramírez y las Casas, menciona a Rivas a propósito de su documentación para el Moro Expósito.

1851 La España, 10 de julio ${ }^{14}$. Sección Folletín, Revista Literaria: dedicado a la leyenda La azucena milagrosa, crítica literaria de Eugenio Ochoa que incluye fragmentos de la obra.

14. Según las palabras de Ochoa, la revista había publicado una nota suya anterior que no hemos encontrado: "Nosotros que tuvimos el gusto de asistir a la primera lectura que hizo de ella el autor en su casa ante una reunión de amigos, dijimos entonces en la España brevemente la grata sensación que nos produjo». 
1851 Semanario Pintoresco Español, n. ${ }^{\circ}$ 3, 19 de enero, La cancela (poema), pp. 23-24. "Peculiar es de Sevilla...».

1853 Museo de las Familias, 25 de junio: "Ocho días de reinado o la verdadera historia de Masaniello», pp. 421-428; continuación el 25 de julio, pp. 145-152; el 25 de agosto, pp. 170-176; el 25 de septiembre, pp. 193-200 y concluye el 25 de octubre, pp. 219-228.

1855 Francisco Pérez de Grandallana narra el regreso del emigrado Rivas en la Revista de Ciencias, Literatura y Artes, tomo III, pp. 638-641 15 .

1855 La Iberia, 4 de marzo. Polémica vinculando al señor Batllés (La Esperanza) con el Duque de Rivas.

1856 Museo de las Familias, 1 de enero: cita unos versos del Duque de Rivas pertenecientes al romance "Una antigualla de Sevilla», en la obra Quien tal hizo, que tal pague, de José Muñoz Gaviria.

1857 Revista Española y Portuguesa, tomo III, p. 522 ${ }^{16}$. Nombramiento de Rivas como embajador en París. 5 de agosto, traducción libre de El desengaño en un sueño (obra de 1842).

1857 La Patria, agosto, artículo sobre Rivas en Francia (p. 46)

$1861 \quad$ Museo de las Familias, 1 de enero: «Una noche en la Cartuja de Pavia», firmado por El conde de Fabraquer. Incluye 4 fragmentos del romance "La victoria de Pavia», del Duque de Rivas.

1862 Revista Ibérica de Ciencias Politicas, 1 de enero. Sección Bibliografía: reseña de la Antología Española. Colección de trozos escogidos de los mejores hablistas, en prosa y verso, desde el siglo XV hasta nuestros dias, por D. Carlos Ochoa. Cita al Duque de Rivas.

1865 La Patria, folletín viernes 3 de junio ${ }^{17}$. Sobre un proyecto de novela de Rivas. Anónimo.

1865 El Ángel del Hogar, 30 de junio. Sección Revista de la semana: Necrológica del Duque de Rivas realizada por Eusebio Blasco.

1865 Museo de las familias, 1 de julio. Estudios biográficos: Rivas, por José Muñoz Gaviria (Necrología sobre el Duque de Rivas). Incluye un soneto de Juan Nicasio Gallego donde cita al escritor.

1865 Escenas Contemporáneas, 1 de julio. Necrología sobre el Duque de Rivas realizada por Leopoldo Augusto Cueto, pp. 238-239. Ídem realizada por José Amador de los Ríos, pp. 305-307.

15. No lo hemos encontrado.

16. No lo hemos encontrado.

17. No lo hemos encontrado.

Anales, 25, 2013, pp. 69-88 
1865 El Museo Universal, 2 de julio. Gustavo A. Bécquer: «El Duque de Rivas». Necrológica.

1867 El Tajo, 16 de junio, Santoral y efemérides: se recuerda el fallecimiento del Duque de Rivas.

1867 Museo de las Familias, 1 de enero: «La Vila Real en Nápoles. Francisco II.- El Duque de Rivas.- Mercadante», firmado por F. Se explica la anecdótica visita del embajador de España, el duque de Rivas, a la Vila Real en Nápoles.

1875 La Ilustración Española y Americana, 15 de diciembre. Las tertulias de Rivas contadas por Leopoldo A. Cueto, pp. 373-375; también sobre El desengaño en un sueño.

1875 La Ilustración Española y Americana, 22 de junio. Poema «Epistola, al Excmo Sr. D. Juan Nicasio Gallego» de Patricio de la Escosura. Cita a numerosos escritores, entre ellos a Rivas.

1882 Escenas Contemporáneas, 1 de enero. Sección «El Arpa del Trovador. Composiciones selectas de los más distinguidos poetas del siglo XIX». Incluye los poemas de Rivas: «En el álbum de un napolitano» $y$ «Versos escritos en un album».

1882 Gil Blas: «Viaje a Andalucía» de Florencio Moreno Godino: menciona a Rivas.

$1884 \quad L a$ Abeja: se informa de la representación, en el Teatro del Príncipe el 5 de julio, de Tanto vales cuanto tienes.

1890 La España Moderna, 1 de julio: «La metafísica y la poesía ante la ciencia moderna», de Campoamor. Introduce una valoración de la poesía de Rivas realizada por Valera.

1890 Almanaque de la Ilustración, pp. 10-24. Luis Vidart: «El Duque de Rivas, Apuntes Biográficos».

$1891 \quad$ La Dinastía, 10 de julio. Se informa de la representación de Don Álvaro o la fuerza del sino en Cataluña.

1892 La Dinastía, 24 de noviembre. Extenso artículo sobre la representación, en el teatro Principal de Barcelona, del Don Álvaro...; acompañado de las ilustraciones del realizador artístico del periódico Manuel González Simancas sobre los decorados de la obra realizados por Amalio Fernández.

1892 La Ilustración Española y Americana, 12 de octubre, IV centenario del Descubrimiento de América. Incluye el poema «Cristobal Colón» de Rivas, fechado en Londres, 1824. 
1894 La España Moderna, 1 de julio. «Impresiones literarias» de F. F. Villegas, pp. 191-201. Cita a Rivas, entre otros autores, al tratar de las nuevas tendencias en el teatro.

1896 La Dinastía, 22 de noviembre. Sección «Ecos Teatrales», informa de la representación, en el teatro Novedades de Barcelona, de Don Álvaro o la fuerza del sino.

\section{Bibliografía}

Alonso Seonne, M. ${ }^{a}$ José, «La defensa del presente en El Artista y el nuevo canon romántico», en La elaboración del canon en la literatura española del siglo XIX, Luis F. Díaz Larios et al. (eds.), Barcelona, Universidad de Barcelona, 2002, pp. 11-26.

AlONSO SEOANE, M. ${ }^{a}$ José et al., El artículo literario y la narrativa breve del romanticismo español, Madrid, Castalia, 2004.

AyAla ARACIL, M. ${ }^{a}$ de los Ángeles, «La defensa de lo romántico en la revista literaria El Artista», en Los románticos teorizan sobre sí mismos, Bolonia, Il Capitello del Sole, 2002, pp. 35-46.

Arroyo Almaraz, Antonio, «Rivas y Larra» en Larra. Fígaro de vuelta (18092009). Vol. I Larra. Actas de conferencias. Bicentenario (1809-2009). Sociedad Estatal de Conmemoraciones Culturales, Madrid, 2009, pp. 319-334.

Arroyo Almaraz, Antonio, et al., (eds.): Ángel Saavedra. Escritor emblemático del Romanticismo español, Chile, Ediciones Universidad de La Frontera, 2010a. Dentro de la obra: «Prólogo» (pp. 6-8) y «Carta de Antonio Ranz Romanillos a Ángel Saavedra, a propósito de la tragedia Doña Blanca de Castilla» (pp. 2342); versión electrónica.

ARroyo Almaraz, Antonio, «Documentación complementaria sobre Doña Blanca de Castilla, de Ángel Saavedra, Duque de Rivas: edición de la carta de Antonio Ranz Romanillos (1819)», en Revista de Filología Románica, Vol. 27, Publicaciones Universidad Complutense de Madrid, (2010b), pp. 363-376.

ARroyo Almaraz, Antonio, «La clave americana en el imaginario romántico: Ángel Saavedra, Duque de Rivas», en Cuadernos de Ilustración y Romanticismo, N. ${ }^{\circ}$ 18. La Península para uso de ingleses: libros británicos de materia española 1800-1850 (sección Miscelánea). Revista Digital del Grupo de Estudios del Siglo XVIII, ISSN 2173-0687, Universidad de Cádiz (UCA), (2012a), pp. 251-262.

Arroyo Almaraz, Antonio (ed.): Literatura y prensa romántica [El Artista y el Semanario Pintoresco Español en sus aniversarios], rev. Arbor, vol. 188, n. ${ }^{\circ}$ 757, septiembre-octubre. Madrid, CSIC, (2012b). Dentro de la obra: «Presentación» (pp. 845-846) y «América como texto y como pretexto en El Artista» (pp. 937-944).

Anales, 25, 2013, pp. 69-88 
Boussagol, Gabriel, Ángel de Saavedra, duc de Rivas. Sa vie, son oeuvre poétique. Toulouse, Imprimerie et librairie Édouard Privat, 1926.

MARTínez TORRón, Diego, El universo literario del Duque de Rivas, Sevilla, Alfar, 2009.

Fecha de recepción: 03/04/2013

Fecha de aceptación: 10/07/2013 